\title{
New Molecules Modulating Bone Metabolism - New Perspectives in the Treatment of Osteoporosis
}

\author{
I. ZOFKOVA ${ }^{1}$, J. BLAHOS ${ }^{2}$ \\ ${ }^{1}$ Institute of Endocrinology, Prague, Czech Republic, ${ }^{2}$ Osteocentrum, Central Military Hospital, \\ Prague, Czech Republic
}

Received March 1, 2017

Accepted April 28, 2017

\section{Summary}

In this review the authors outline traditional antiresorptive pharmaceuticals, such as bisphosphonates, monoclonal antibodies against RANKL, SERMs, as well as a drug with an anabolic effect on the skeleton, parathormone. However, there is also a focus on non-traditional strategies used in therapy for osteolytic diseases. The newest antiosteoporotic pharmaceuticals increase osteoblast differentiation via BMP signaling (harmine), or stimulate osteogenic differentiation of mesenchymal stem cells through Wnt/ $\beta$-catenin (icarrin, isoflavonoid caviunin, or sulfasalazine). A certain promise in the treatment of osteoporosis is shown by molecules targeting non-coding microRNAs (which are critical for osteoclastogenesis) or those stimulating osteoblast activity via epigenetic mechanisms. Vitamin D metabolites have specific antiosteoporotic potencies, modulating the skeleton not only via mineralization, but markedly also through the direct effects on the bone microstructure.

\section{Key words}

RANKL • Sclerostin • Cathepsin $\mathrm{K} \bullet \mathrm{Wnt} / \beta$-catenin • Estrogen • SERM • Bisphosphonates • Parathormone • Vitamin D • MicroRNA

- Bone mineralization • Bone microarchitecture

\section{Corresponding author}

I. Zofkova, Institute of Endocrinology, Narodni 8, 11694 Prague, Czech Republic. E-mail: izofkova@upcmail.cz

\section{Introduction}

Osteoporosis is a serious public health problem. In the Czech Republic around 500,000 women and 200,000 men are affected by the disease. The osteoporotic population is endangered by increased morbidity and mortality due to fractures and their deteriorated healing, primarily in elderly, frail patients with a number of comorbidities and medicament therapies. Genetically determined both sensitivity and the side effects of therapy may complicate the choice of suitable long-term antiosteoporotic treatment in individual patients. This article reviews traditionally used antiosteoporotics and some recently discovered molecules with beneficial effects on the skeleton.

Under physiological conditions, bone is permanently remodeled to maintain its volume, microstructure and strength. When bone resorption predominates over formation, bone mass is endangered by progressive loss. The first choice of treatment in this case are usually bisphosphonates, drugs discovered 45 years ago. Bisphosphonates antagonize osteoclastogenesis through various mechanisms of action (Mac-Way et al. 2014, Nataka et al. 2015). Long-term oral or parenteral bisphosphonate therapy increases bone mineral density (BMD), bone volume, reduces bone porosity and markedly decreases fracture risk. A feature of this treatment is also its low cost. However, bisphosphonate therapy may be complicated by some serious side effects. Besides gastrointestinal intolerance, both oral and parenteral bisphosphonates may induce osteonecrosis of the jaw and/or atypical femoral fractures, partly explained by the inhibition of healing near bone cracks (Pazianas et al. 2016, Adler 2016). Furthermore, bisphosphonates are only marginally effective in patients with severe loss of bone mass, although effectivity of treatment may be improved by an advantageous pharmaceutical scheme, in 
which bisphosphonate modified nanomaterials (conjugates with protein and polymers) directly target the bone and optimize drug delivery control (Ossipov 2015). The benefit/risk ratio in bisphosphonate therapy should be taken into account during the long-term process, which often requires more than one type of antiresorptive treatment.

Selective estrogen receptors modulators (SERMs) and their new analogs represent effective variant of antiresorptive therapy. With the exception of tamoxifen, raloxifene and lasofoxifene, a third generation molecule - bazedoxifene was synthesized. The latter drug significantly reduced the incidence of both vertebral and nonvertebral fractures in postmenopausal osteoporotic women. The pharmaceutical has been found safe in relation to endometrial and breast cancerogenesis (Komm and Chines 2012, An 2016).

Biological therapy has a good potential for increasing bone mass. The monoclonal antibody against RANKL, denosumab has positive effects on the microarchitecture of the skeleton (inhibition of erosion development and increase in cortical thickness and bone stiffness) (Bonani et al. 2016). Kamimura et al. (2017) showed inhibition of bone resorption and an increase in lumbar and hip BMD after one year of treatment with denosumab in patients unresponsive to bisphosphonate. Nevertheless, similar to bisphosphonates, a certain limitation of long-term denosumab treatment may be the reduced renewal of bone mass with subsequent osteonecrosis of the jaw and/or atypical femoral fractures (Qaisi et al. 2016).

Any inhibition of the cytokine network appears to slow down bone loss. Zerbini et al. (2017) analyzed clinical studies, in which patients with rheumatoid arthritis were treated with anti-TNF antibodies (such as infliximab, adalimumab, etanercept), or IL-1 and IL-6 antagonists (abatacept or rituximab). Although some patients in this study showed significant increase in BMD, others remained unafected. Moreover, there was no consensus regarding their effects on fracture risk.

Bone formation is known to be stimulated via the Wnt/ $\beta$-catenin pathway (Mosekilde et al. 2011). This pathway (expressed by osteocytes) is under the control of the SOST gene (located at chromosome region 17q12-q21) and inhibited by sclerostin. Mutations in SOST are known to be associated with low sclerostin level and increased bone mass. Undetectable sclerostin levels are manifested as autosomal-recessive sclerosteosis (Yavropoulou et al. 2014). On the other hand, bone diseases, such as osteoporosis, bone metastases and genetically dependent low bone mass, are often associated with sclerostin overproduction.

The inconvenience of antiresorption therapy could be eliminated by using exclusively anabolic pharmaceuticals, such as intact PTH (1-84) (preotact) or PTH (1-34) (teriparatide). At the present time, teripartide is the only currently available bone anabolic molecule working via the inhibition of sclerostin and other metabolic circuits, such as DKK1 and/or frizzled protein. Small pulsatile doses of exogenous PTH increase BMD, improve microarchitecture and bone strength (Mosekilde et al. 2011), which results in lowering the fracture risk (reviewed by Tella and Gallagher 2014, Ishitaq et al. 2015). Cancellous bone density increased and trabecular separation decreased in postmenopausal women with osteoporosis treated with teriparatide irrespective of previous bisphosphonate administration (FahrleitnerPammer et al. 2016). There is no consensus on teriparatide treatment in osteoporotic diabetics. However, incretin derivatives, such as GLP-1 and GIP, appear to have good prospects in the prevention or treatment of osteoporosis in diabetics. After binding to osteoblastic receptors, there is an increase in bone formation (NucheBerenguer et al. 2009, Yamada 2012).

An alternative to exogenous PTH is the endogenous molecule, the secretion of which is stimulated through the inhibition of the calcium sensing receptor (CASR) (Widler 2011). A strong anabolic effect on the skeleton was also shown in PTH fragments, and PTHrP analog (abaloparatide), which are currently under investigation (Yamaguchi 2016).

Effectivity on fracture healing is strengthened when teriparatide is combined with other antiosteoporotics. Casanova et al. (2016), using micro CT and quantitative histomorphometry showed that a three week administration of teriparatide together with zolendronic acid significantly increased bone volume and reduced trabecular spacing in mice with operatively induced fractures. Leder et al. (2016) in a randomized control trial described more significant increases in BMD at the hip and at the lumbar spine in postmenopausal women treated for two years with teriparatide and denosumab, when compared with women on single administration of these medicaments. Furthermore, better fracture repair could be obtained using a combination of teriparatide and anti-sclerostin and/or anti-cathepsin $\mathrm{K}$ antibodies (Tella and Gallagher 2014). 
Further new molecules with antisclerostin effects

Subcutaneous administration of monoclonal antisclerostin antibodies, such as AbD09097, stimulates bone formation and increases bone mass through activation of the Wnt pathway, independently of bone remodeling (Boschert et al. 2016, Yavropoulou et al. 2014). Bone anabolic effects also have other antibodies against sclerostin, such as romosozumab or blosozumab. Both these drugs were successfully tested experimentally (reviewed by Tella and Gallagher 2014) and clinical trials in phase II are under way (Matsumoto 2015). Recently, the dose dependent stimulating effect of romosozumab on BMD at the spine was shown in 419 women with postmenopausal osteoporosis. The effect was markedly higher when compared with oral alendronate or the teriparatide (Larsson 2016). Similar effects of romosozumab on volumometric BMD at vertebral and total hip regions were observed in postmenopausal women by Genant et al. (2016). Additionally, a placebo controlled study on 7180 postmenopausal women showed, that romosozumab significantly decreased the risk of vertebral fractures after 12 months of treatment (Cosman et al. 2016).

\section{Substances with anti-cathepsin effects}

A recently discovered molecule with an antiosteoporotic effect is the monoclonal antibody against cathepsin K (CTSK) (Chan et al. 2016). Cathepsin K is a proteolytic enzyme, which degrades collagen $\mathrm{I}$ in the bone matrix and activates bone resorption. The cathepsin $\mathrm{K}$ antibody, due to the coupling between bone resorption and bone formation, inhibits both these processes, but more markedly bone resorption and only transiently bone formation. Long-term administration of cathepsin $\mathrm{K}$ antibodies, such as odanacatib, increased BMD and decreased the fracture rate (Boonen et al. 2012, Tella and Gallagher 2014). Some other cathepsin K inhibitors were evaluated, which are mostly in preclinical trials (Brömme et al. 2016).

\section{Further non-traditional molecules with antiosteoporotic potential}

Osteoclast formation is increased after the activation of T-cells through NF- $\kappa \mathrm{B}$, NFATc1 or c-Fos signaling. In bone tissue culture, this process was inhibited by $\beta$-carboline alkaloid harmine. Additionally, the alkaloid increased osteoblast differentiation via Runx2, osterix and bone morphogenetic peptide (BMP) (Yonezawa et al. 2011). Thus, harmine inhibits bone resorption and simultaneously activates bone formation. According to our knowledge, no study analyzing antiosteoporotic effectivity of the alkaloid in vivo has been published yet.

Certain antiosteoporotic activity was recorded in neoflavonoids, isolated chromatographically from Dalbergia sissoo heartwood. The flavonoids significantly stimulated calvarial osteoblast proliferation and mineralization (Kumar et al. 2014). Similarly, caviuninbased isoflavonoid stimulates bone formation via BMP2 and $\mathrm{Wnt} / \beta$-catenin pathways, effectively inhibits osteoclastogenesis and repairs cortical bone. In ovariectomized mice caviunin increased the mechanical strength of the vertebra and femur (Kushwaha et al. 2014). Similar anabolic effects on the skeleton mediated by $\mathrm{Wnt} / \beta$-catenin signaling have been registered experimentally in aglycone of icariin. Micro-CT analysis showed that icariine after 12-weeks of treatment increased BMD, trabecular bone number, trabecular thickness, reduced trabecular separation and increased biomechanical strength in oophorectomized rats (Chen et al. 2016). Some flavonoids could be positioned as potential pharmaceuticals or food supplements for fracture repair in postmenopausal osteoporosis.

Strong bioactivity in the culture of osteoblastlike cells has been shown in the three-dimensional calcium-bearing structure $\mathrm{CaP} 1$ (which has three molecules of water). In vivo, the substance increased bone mineralization without any toxicity (Shi et al. 2015). Bone regenerative effects were also found in synthetic diether molecules inhibiting RANKL-induced osteoclast formation (Doh et al. 2016), as well as in octacalcium phosphate, which increased bone mineralization via an irreversible transition into hydroxyapatite (Suzuki et al. 2008).

Furthermore, the food-derived compound sulforaphane and natural isothiocyanate promote osteoblast activity via epigenetic mechanisms. The molecule activates DNA demethylation increasing matrix mineralization. In mice it stimulates the expression of osteoblastic markers, such as Runx2, collagen 1A1 or ALP1, while inhibiting the nuclear factor- $\kappa \mathrm{B}$ (RANKL) in osteocytes with subsequent increases in the trabecular number (Thaler et al. 2016). New strategies in therapy for osteolytic diseases consist of targeting non-coding 
microRNAs (miRNAs), which control gene expression in osteoclasts. Thus, miRNAs appear to be the key molecules in the regulation of bone resorption (Li et al. 2016). Bone homemostasis is determined by the osteogenesis/adipogenesis ratio in mesenchymal cells. Prevailing adipogenesis over osteogenesis is a principle pathological factor in accelerated bone loss. A strong modulator of osteogenic differentiation is the glutamate exchanger $\mathrm{xCT}$ (SLC7A11) sulfasalazine, which enhances the osteogenic potential via an increase in BMP2/4 expression. Sulfasalazine administered in vivo inhibited bone loss in hypoestrogenic mice (Jin et al. 2016). Thus, sulfasalazine is a further candidate useful in the treatment of postmenopausal osteoporosis.

Potential bone protecting candidates are also growth factors, such as BMP, fibroblast growth factor (FGF) and vascular endothelial growth factor (VEGF) (Lee et al. 2015). Some of these mediate the action of other molecules (Jin et al. 2016). The beneficial effects of erythropoetin or statins on fracture healing are under investigation; however, sufficient evidence of their antiosteoporotic action in vivo is still lacking (Klontzas et al. 2016).

\section{New aspects of the bone protecting effects of vitamin D}

Vitamin D positively influences not only the mineralization of the bone matrix, but via genomic and non-genomic effects modulates the function of some non-skeletal systems, including muscles. D-hormone metabolites have been shown to influence bone homeostasis directly. Bioactive 25(OH) $\mathrm{D}_{3}$, $1,25(\mathrm{OH})_{2} \mathrm{D}_{3}$, as well as $24 \mathrm{R}, 25(\mathrm{OH})_{2} \mathrm{D}_{3}$ stimulated osteoblast growth and differentiation in vitro (van der Meijden et al. 2014). 1,25(OH) ${ }_{2} \mathrm{D}_{3}$ administered in vivo for 28 consecutive days, significantly increased bone formation, reduced bone resorption and increased trabecular bone volume in mice (Oelzner et al. 2014). Long-term treatment with $1 \alpha, 25[\mathrm{OH}](2)-2 \beta$ (3-hydroxypropyloxy)vitamin $\mathrm{D}_{3}$ metabolite (eldecalcitol) suppressed bone turnover, decreased the risk of bone microstructure deterioration and increased bone biomechanical strength in ovariectomized rats (Takeda et al. 2015). Yamasaki et al. (2015) found that eldelcalcitol increased bone formation at the endocortical surface in female rats.

In clinical studies, significant increases in BMD in the spine of osteopenic women were found at the end of the 1st, 2nd and 3rd years of treatment with $1,25(\mathrm{OH})_{2} \mathrm{D}_{3}$, while no positive effects in cholecalcipherol treated women were observed (Zofkova and Hill 2007). Thus, it can be said that D-hormone metabolites have unambiguously positive effects on bone mass and microstructure.

\section{Conclusion}

Although a relatively good spectrum of molecules with osteogenic potential is available at the present time, their effects (positive or even detrimental) on the skeleton may differ in individual subjects depending on their genetic predisposition. New strategies in the therapy of osteolytic diseases using drugs with satisfactory beneficial potential for the skeleton and absent or minimal side effects are necessary. Identification of candidate genes (e.g. LRP5, PSL3 and WNT1) associated with the response of bone mass and bone quality to individual pharmaceuticals will make it possible to personalize curative strategies (reviewed by Rocha-Braz and Ferraz-de-Souza 2016, Zofkova et al. 2015).

\section{Conflict of Interest}

There is no conflict of interest.

\section{Acknowledgements}

This work was supported by the project (Ministry of Health, Czech Republic), for conceptual development of research organization 00023761 (Institute of Endocrinology, Prague, Czech Republic) and by the MEYS CR (OP RDE, Excellent research - ENDO.CZ).

\section{References}

ADLER RA: Bisphosphonates and atypical femoral fractures. Curr Opin Endocrinol Diabetes Obes 23: 430-434, 2016. AN KC: Selective estrogen receptor modulators. Asian Spine J 10: 787-791, 2016.

BONANI M, MEYER U, FREY D, GRAF N, BISCHOFF-FERRARI HA, WÜTHRICH RP: Effect of denosumab on peripheral compartmental bone density, microarchitecture and estimated bone strength in de novo kidney transplant recipients. Kidney Blood Press Res 41: 614-622, 2016. 
BOONEN S, ROSENBERG E, CLAESSENS F, VANDERSCHUEREN D, PAPAPOULOS S: Inhibition of cathepsin K for treatment of osteoporosis. Curr Osteoporos Rep 10: 73-79, 2012.

BOSCHERT V, FRISCH D, BACK JW, VAN PEE K, WEIDAUER SE, MUTH EM, SCHMIEDER P, BEERBAUM M, KNAPPIK A, TIMMERMAN P, MUELLER TD: The sclerostin-neutralizing antibody AbD09097 recognizes an epitope adjacent to sclerostin's binding site for the Wnt co-receptor LRP6. Open Biol 6: 160120, 2016.

BRÖMME D, PANWAR P, TURAN S: Cathepsin K osteoporosis trials, pycnodysostois and mouse deficiency models: commonalities and differences. Expert Opin Drug Discov 11: 467-472, 2016.

CASANOVA M, HERELLE J, THOMAS M, SOFTLEY R, SCHINDELER A, LITTLE D, SCHNEIDER P, MÜLLER $\mathrm{R}$ : Effect of combined treatment with zolendronic acid and parathyroid hormone on mouse bone callus structure and composition. Bone 92: 70-78, 2016.

CHAN CK, MASON A, COOPER C, DENNISON E: Novel advances in the treatment of osteoporosis. Br Med Bull 118: 129-142, 2016.

CHEN G, WANG C, WANG J, YIN S, GAO H, XIANG LU, LIU H, XIONG Y, WANG P, ZHU X, YANG LI, ZHANG R: Antiosteoporotic effect of icariin in ovariectomized rats is mediated via Wnt/ $\beta$-catenin pathway. Exp Ther Med 12: 279-287, 2016.

COSMAN F, CRITTENDEN DB, ADACHI JD, BINKLEY N, CZERWINSKI E, FERRARI S, HOFBAUER LC, LAU E, LEWIECKI EM, MIYAUCHI A, ZERBINI CA, MILMONT CE, CHEN L, MADDOX J, MEISNER PD, LIBANATI C, GRAUER A: Romosozumab treatment in postmenopausal women with osteoporosis. $N$ Engl J Med 375: 1532-1543, 2016.

DOH KE, KANG JH, TING Z, YIM M, CHOO HY: Novel diether compounds inhibiting differentiation of osteoclasts. Arch Pharm Res 39: 178-190, 2016.

FAHRLEITNER-PAMMER, BURR D, DOBNIG H, STEPAN JJ, PETTO H, LI J, KREGE JH, PAVO I: Improvement of cancellous bone microstructure in patients on teriparatide following alendronate pretreatment. Bone 89: 16-24, 2016.

GENANT HK, ENGELKE K, BOLOGNESE MA, MAUTALEN C, BROWN JP, RECKNOR C, GOEMAERE S, FUERST T, YANG YC, GRAUER A, LIBANATI C: Effects of romosozumab compared with teriparatide on bone density and mass at the spine and hip in postmenopausal women with low bone mass. J Bone Miner Res 32: 181-187, 2016.

ISHTIAQ S, FOGELMAN I, HAMPSON G: Treatment of post-menopausal osteoporosis: beyond bisphosphonates. J Endocrinol Invest 38: 13-29, 2015.

JIN C, ZHANG P, ZHANG M, ZHANG X, LV L, LIU H, LIU Y, ZHOU Y: Inhibition of SLC7A11 by sulfasalazine enhances osteogenic differentiation of mesenchymal stem cells by modulating BMP2/4 expression and suppresses bone loss in ovariectomized mice. J Bone Mineral Res 32: 508-521, 2016.

KAMIMURA M, NAKAMURA Y, IKEGAMI S, UCHIYAMA S, KATO H, TAGUCHI A: Significant improvement of bone mineral density and bone turnover markers by denosumab therapy in bisphosphonate-unresponsive patients. Osteoporos Int 28: 559-566, 2017.

KLONTZAS ME, KENANIDIZ EI, MACFARLANE RJ, MICHAIL T, POTOUPNIS ME, HELIOTIS M, MANTALARIS A, TSIRIDIS E: Investigational drugs for fracture healing: preclinical and clincal data. Expert Opin Investing Drugs 25: 585-596, 2016.

KOMM BS, CHINES AA: Bazedoxifene: the evolving role of third-generation selective estrogen-receptor modulators in the management of postmenopausal osteoporosis. Ther Adv Musculoskelet Dis 4: 21-34, 2912.

KUMAR P, KUSHWAHA P KHEDGIKAR V, GAUTAM J, CHOUDHARY D, SINGH D, TRIVEDI R, MAURYA R: Neoflavonoids as potential osteogenic agents from Dalbergia sissoo heathwood. Bioorg Med Chem Lett 24: 2664-2668, 2014.

KUSHWAHA P, KHEDGIKAR V, GAUTAM J, DIXIT P, CHILLARA R, VERMA A, THAKUR R, MISHRA DP, SINGH D, MAURYA R, CHATTOPADHYAY N, MISHRA PR, TRIVEDI R: A novel therapeutic approach with Caviunin-based isoflavonoid that en routes bone marrow cells to bone formation via BMP2/Wnt- $\beta$ catenin signaling. Cell Death Dis 5: e1422, 2014.

LARSSON S: Anti-sclerostin - is there an indication? Injury 47 (Suppl 1): S31-S35, 2016. 
LEDER BZ, TSAI JN, NEER RM, UIHLEIN AV, WALLACE PM, BURNETT-BOWIE SA: Response to therapy with teriparatide, denosumab, or both in postmenopausal women in the DATA (denosumab and teriparatide administration) Study Randomized Controlled Trial. J Clin Densitom 19: 346-351, 2016.

LEE ZH, KIM HJ, RYOO HM: A novel oesteogenic activity of suberoylanilide hydroxamic acid is synergized by BMP-2. J Bone Metab 22: 51-56, 2015.

LI H, ZHAI Z, QU X, XU J, QIN A, DAI K: MicroRNAs as potential targets for treatment of osteoclast-related diseases. Curr Drug Targets in press 2016.

MAC-WAY F, TROMBETTI A, NOEL C, LAFAGE-PROUST MH: Giant osteoclasts in patients under bisphosphonates. BMC Clin Pathol 14: 31, 2014.

MATSUMOTO T: Pharmacology of bone anabolic agents. Nihon Rinsho 73: 1639-1644, 2015.

MOSEKILDE L, TORRING O, REJNMARK L: Emerging anabolic treatments in osteoporosis. Curr Drug Saf 6: 62-74, 2011.

NAGAOKA Y, KAJIYA H, OZEKI S, IKEBE T, OKABE K: Mevalonates restore zolendronic acid-induced osteoclastogenesis inhibition. J Dent Res 94: 594-601, 2015.

NUCHE-BERENGUER B, MORENO P, ESBRIT P, DAPIA S, CAREIRO JR, CANCELAS J, HARO-MORA JJ, VILLANUEVA-PEŇACRILLO ML: Effect of GLP-1 treatment on bone turnover in normal, type 2 diabetic, and insulin-resistant states. Calcif Tissue Int 84: 453-461, 2009.

OELZNER P, PETROW PK, WOLF G, BRÄUER R: 1,25-dihydroxyvitamin D3 prevents bone loss of the secondary spongiosa in arthritic rats by an increase of bone formation and mineralization and inhibition of bone resorption. BMC Musculoskelet Disord 15: 345, 2014.

OSSIPOV DA: Bisphosphonate-modified biomaterials for drug delivery and bone tissue engineering. Expert Opin Drug Deliv 12: 1443-1458, 2015.

PAZIANAS M, ABRAHAMSEN B: Osteoporosis treatment: bisphosphonates reign to continue for a few more years, at least? Ann N Y Acad Sci 1376: 5-13, 2016.

QAISI M, HARGETT J, LOEB M, BROWN J, CALOSS R: Denosumab related osteonecrosis of the jaw with spontaneous necrosis of the soft palate: report of a life threatening case. Case Rep Dent 2016: 5070187, 2016.

ROCHA-BRAZ MG, FERRAZ-DE-SOUZA B: Genetics of osteoporosis: searching for candidate genes for bone fragility. Arch Endocrinol Metab 60: 391-401, 2016.

SHI FN, ALMEIDA JC, HELGUERO LA, FERNANDES MH, KNOWLES JC, ROCHA J: Calcium phosphonate framewoks for treating bone tissue disorders. Inorg Chem 54: 9929-9935, 2015.

SUZUKI O, IMAIZUMI H, KAMAKURA S, KATAGIRI T: Bone regeneration by synthetic octacalcium phosphate and its role in biological mineralization. Curr Med Chem 15: 305-313, 2008.

TAKEDA S, SMITH SY, TAMURA T, SAITO H, TAKAHASHI F, SAMADFAM R, HAILE S, DOYLE N, ENDO $\mathrm{K}$ : Long-term treatment with eldecalcitol (1 $\alpha, 25$-dihydroxy-2 $\beta$-(3-hydroxypropyloxy) vitamin D3) suppresses bone turnover and leads to prevention of bone loss and bone fragility in ovariectomized rats. Calcif Tissue Int 96: 45-55, 2015.

TELLA SH, GALLAGHER JC: Biological agents in management of osteoporosis. Eur J Clin Pharmacol 70: 1291-1301, 2014.

THALER R, MAURIZI A, ROSCHGER P, STURMLECHNER I, KHANI F, SPITZER S, RUMPLER M, ZWERINA J, KARLIC H, DUDAKOVIC A, KLAUSHOFER K, TETI A, RUCCI N, VARGA F, VAN WIJNEN AJ: Anabolic and antiresorptive modulation of bone homeostasis by the epigenetic modulator sulforaphane, a naturally occurring isothiocyanate. J Biol Chem 291: 6754-6771, 2016.

VAN DER MEIJDEN K, LIPS P, VAN DRIEL M, HEIJBOER AC, SCHULTEN EA, DEN HEIJER M, BRAVENBOER $\mathrm{N}$ : Primary human osteoblasts in response to 25-hydroxyvitamn D3, 1,25-dihydroxyvitamin D3 and 24R,25dihyroxyvitamin D3. PLoS One 9: e110283, 2014.

WIDLER L: Catalytics: antagonists of the calcium-sensing receptor for the treatment of osteoporosis. Future Med Chem 3: 535-547, 2011.

YAMADA Y: Diabetes mellitus and osteoporosis. Incretin as a coordinator of glucose and bone metabolism. Clin Calcium 22: 1353-1358, 2012.

YAMAGUCHI M: The importance of teriparatide in the treatment of osteoporosis. Clin Calcium 26: 905-913, 2016. 
YAMASAKI Y, NAGIRA K, OSAKI M, NAGASHIMA H, HAGINO H: Effects of eldecalcitol on cortical bone response to mechanical loading in rats. BMC Musculoskelet Disord 16: 158, 2015.

YAVROPOULOU MP, XYGONAKIS C, LOLOU M, KARADIMOU F, YOVOS JG: The sclerostin story: from human genetics to the development of novel anabolic treatment for osteoporosis. Hormones (Athens) 13: 323-337, 2014.

YONEZAWA T, LEE JW, HIBINO A, ASAI M, HOJO H, CHA BY, TERUYA T, NAGAI K, CHUNG UI, YAGASAKI K, WOO JT: Harmine promotes osteoblast differentiation through bone morphogenetic protein signaling. Biochem Biophys Res Commun 409: 260-265, 2011.

ZERBINI CA, CLARK P, MENDEZ-SANCHEZ L, PEREIRA RM, MESSINA OD, UÑA CR, ADACHI JD, LEMS WF, COOPER C, LANE NE, IOF CHRONIC INFLAMATION AND BONE STRUCTURE (CIBS) WORKING GROUP: Biologic therapies and bone loss in rheumatoid arthritis. Osteoporos Int 28: 429-446, 2017.

ZOFKOVA I, HILL M: Long-term 1,25(OH)2 vitamin D therapy increases bone mineral density in osteopenic women. Comparison with the effect of plain vitamin D. Aging Clin Exp Res 19: 472-477, 2007.

ZOFKOVA I, NEMCIKOVA P, KUKLIK M: Polymorphisms associated with low bone mass and high risk of atraumatic fracture. Physiol Res 64: 621-631, 2015. 